\title{
Analysis of the Association of Foramen Cecum and Dens in Dente in Maxillary Lateral Incisor
}

\author{
Luis Eduardo Genaro ${ }^{1}$ Marcelo Brito Conte ${ }^{1}$ Giovana Anovazzi ${ }^{1}$ Andréa Gonçalves ${ }^{2}$ \\ Marcela de Almeida Gonçalves ${ }^{1}$ Ticiana Sidorenko de Oliveira Capote ${ }^{1}$ \\ ${ }^{1}$ Department of Morphology, Genetics, Orthodontic and Pediatric \\ Dentistry, School of Dentistry, São Paulo State University, \\ Araraquara, São Paulo, Brazil \\ 2Department of Diagnosis and Surgery, School of Dentistry, São \\ Paulo State University, Araraquara, São Paulo, Brazil

\begin{abstract}
Address for correspondence Luis Eduardo Genaro, DDS, Department of Morphology, Genetics, Orthodontic and Pediatric Dentistry, School of Dentistry, São Paulo State University (UNESP), Rua Humaitá, 1680, 14801-903 Araraquara, SP, Brazil
\end{abstract} \\ (e-mail: luis-genaro@outlook.com).
}

\begin{abstract}
Keywords

- anatomy

- incisor

- dens in dente

Objectives The aim of this study was to evaluate the frequency of foramen cecum and dens in dente, and to verify the association of these structures in the maxillary lateral incisor (MLI).

Materials and Methods The presence of foramen cecum in the lingual surface of $110 \mathrm{MLI}$ was verified, and the teeth were radiographed to observe the presence of dens in dente, being classified according to the literature. An association study between the presence of foramen cecum and dens in dente was performed using the Cramer's $V$ and chi-square statistical tests.

Results The association was statistically significant between the foramen cecum and the dens in dente. Concomitant presence was observed in $17.27 \%$, being a high rate when compared with the presence of foramen cecum alone $(9.09 \%)$ or dens in dente alone (8.18\%). In addition, type I (minimal invagination, confined to the crown of the tooth and not extending beyond the level of the cementum-enamel junction) was the most frequent (82.14\%).

Conclusions We emphasize the importance of alerting the dentist to the presence of a foramen cecum on the lingual surface of the MLI, as it is likely that dens in dente is usually of type I. Thus, the foramen cecum is a sign that can assist the dental surgeon in the discovery of dens in dente and clinical conduct to be taken.
\end{abstract}

\section{Introduction}

The term dens in dente, also classified as dens invaginatus, is used to denote an anomaly that affects the tooth during its formation, resulting from invagination of coronary tissues. ${ }^{1,2}$ On radiographs, the enamel appears outlined, giving the impression of a "small tooth inside another.",3 This anomaly was classified according to its different forms of presentation into three types, regarding depth and communication with periapical tissue or periodontal ligament.,

The etiology of this malformation is idiopathic, but the pressure or physical forces such as accidental infection of

published online

October 5, 2020
DOI https://doi.org/

$10.1055 / s-0040-1717157$ ISSN 1305-7456. the tooth germ, traumatic injuries produced in the contact between two developing teeth, the genetic predisposition and ethnic differences, failures in the growth of the internal enamel epithelium, rapid proliferation and aggressive alteration of the enamel, and fusion process were reported as possible causes of the development of this anomaly. ${ }^{3,6,7}$

It is also reported in the literature that the dens in dente arises from a deep fold of the foramen cecum during tooth development which in some cases may result in a second apical foramen. ${ }^{7}$ The affected tooth demonstrates a deep invagination of enamel and dentin from the foramen cecum and can be deeply extended to the root. Thus, the foramen cecum may

(C) 2020. European Journal of Dentistry.

This is an open access article published by Thieme under the terms of the Creative Commons Attribution-NonDerivative-NonCommercial-License, permitting copying and reproduction so long as the original work is given appropriate credit. Contents may not be used for commercial purposes, or adapted, remixed, transformed or built upon. (https://creativecommons.org/licenses/by-nc-nd/4.0/)

Thieme Medical and Scientific Publishers Pvt. Ltd., A-12, 2nd Floor, Sector 2, Noida-201301 UP, India 
be the first clinical sign indicating the presence of this malformation. ${ }^{8}$ In many cases, the dens in dente predisposes to pulp disease, as the dentin of the invaginated area can be exposed directly to the oral environment. ${ }^{4,6,8}$ So, the foramen cecum can be a sign to be considered by the dentist who can indicate the presence of dens in dente and with an initial conservative clinical treatment, it is possible to preserve the dental element.

The most affected teeth are the maxillary lateral incisors (MLIs). ${ }^{6,9}$ Bilateral occurrence is not uncommon and occurs in $43 \%$ of all cases. ${ }^{10}$ MLI usually varies more than any other tooth, and when those variations are marked, they are called developmental anomalies. ${ }^{6}$

Researching science bases such as BIREME, Google Scholar, SciELO, Scopus, and PubMed over the past 20 years, using the keywords "dens in dente," "dens invaginatus," "lateral incisor anatomy," "foramen caecum," "maxillary incisor morphology," we found that several articles were related. However, only two articles were related to the association of foramen cecum in MLI and dens in dente; however, no article studied and described the frequency of foramen cecum. Most studies were related to clinical cases, especially in the area of endodontics. Therefore, based on the scarcity of published researches, we noted the importance of studying this feature.

Thus, the objective of this study was to evaluate the frequency of the foramen cecum in the MLI and to verify its association with dens in dente. It is worth mentioning that this is an unprecedented study, as no study related to the frequency of the foramen cecum in the MLI was found. The null hypothesis is that there is no association between foramen cecum and dens in dente.

\section{Materials and Methods}

This project was approved by the ethics committee of the School of Dentistry, São Paulo State University (UNESP), Araraquara, São Paulo, Brazil (CAAE 01520318.0.0000.5416).

We evaluated 110 MLIs, belonging to the collection of the Anatomy Laboratory, Department of Morphology, Genetics, Orthodontics and Pediatric Dentistry, School of Dentistry, Araraquara, São Paulo, Brazil. Those teeth are used in dental anatomy classes by dentistry students. The teeth have no identification of the donor's sex, age, and ethnicity. Healthy teeth, without caries, restorations, or fractures were included. The MLIs with any of these conditions were not evaluated.

The teeth were analyzed by direct evaluation for the presence of cecum foramen on the lingual surface.

The MLIs were radiographed to verify the presence of dens in dente, using a 70-kVp, 7-mA, and 0.16-second digital Instrumentarium FOCUS model X-ray machine at the Department of Diagnosis and Surgery, School of Dentistry, São Paulo State University (UNESP), Araraquara, São Paulo, Brazil.

To obtain the images, the phosphor plate (Dürr Dental) remained on a flat surface; on this phosphor plate, the following was placed: (1) the tooth, (2) an initial letter for further image identification, and (3) a density scale. The X-ray beam was perpendicular to the tooth being radiographed. Phosphor plates were scanned and radiographic images were saved in tiff format for viewing in the image viewing software (DBSWIN, Dürr Dental).

The teeth that presented dens in dente were classified according to Oehlers: ${ }^{4}$

Type I: Invagination is minimal, confined to tooth crown and does not extend beyond the level of the cementumenamel junction.

Type II: Invagination extends into the pulp cavity but remains within the root canal without communication with the periodontal ligament.

Type III: Invagination extends through the root and laterally communicates with the periodontal ligament through a pseudoforamen. There is usually no communication with the pulp, which is compressed within the root.

An association study between the presence of foramen cecum and dens in dente was performed using the Cramer's $\mathrm{V}$ test, and the chi-square test was used to verify statistical significance.

\section{Results}

- Table 1 shows the frequency and association of foramen cecum with dens in dente in the MLI.

The chi-square independence test was performed between the variables foramen cecum and dens in dente. All expected frequencies were higher than five. There was a statistically significant association between foramen cecum and dens in dente, chi-square test $=27,063$, with $p<0.005$. The association was moderately strong with a Cramer's V test of 0.528 .

The present study provides quantitative data on the frequency of the foramen cecum, which can be seen in 29 MLIs (26.36\%), which is important when the association of foramen cecum and dens in dente the tooth is observed, as is the case.

Concomitant presence was observed in $17.27 \%$, being a high rate when compared with the presence of foramen cecum alone $(9.09 \%)$ or dens in dente alone $(8.18 \%)$. In addition, type I (minimal invagination, confined to the crown of the tooth and not extending beyond the level of the cementum-enamel junction) was the most frequent (82.14\%).

-Figs. 1 to 5 illustrate the MLI morphology and the absence or presence of dens in dent.

\section{Discussion}

Although classic dental anatomy books report the foramen cecum as a very common structure on the lingual surface of the MLI, the number of research studies related to this

Table 1 Frequency and association of foramen cecum with dens in dente

\begin{tabular}{|l|l|l|l|}
\hline \multirow{2}{*}{$\begin{array}{l}\text { Dens in } \\
\text { dente }\end{array}$} & \multicolumn{3}{|c|}{ Foramen cecum } \\
\cline { 2 - 4 } Present (\%) & $19(17.27)$ & $9(8.18)$ & $28(25.36)$ \\
\hline Absent (\%) & $10(9.09)$ & $72(65.45)$ & $82(74.54)$ \\
\hline Total (\%) & $29(26.36)$ & $81(73.63)$ & $110(100)$ \\
\hline
\end{tabular}



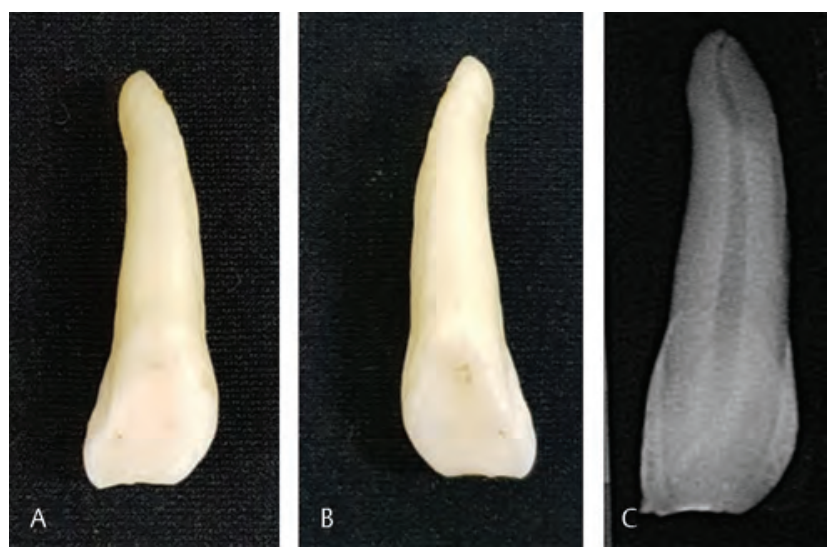

Fig. 1 (A) Morphology of the buccal surface of the MLI. (B) Morphology of the lingual surface of the MLI. (C) Digital radiography of the MLI without foramen cecum and dens in dente (a "normal" MLI). MLI, maxillary lateral incisor.
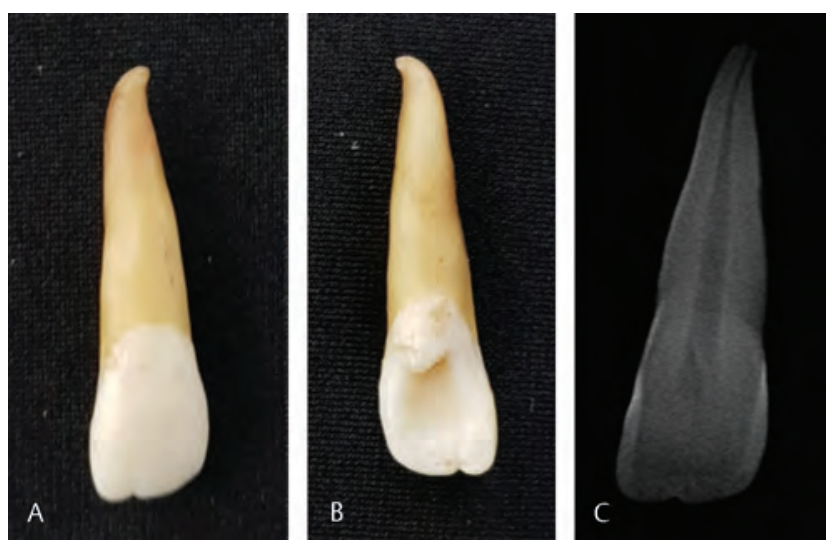

Fig. 2 (A) Morphology of the buccal surface of the MLI.(B) Morphology of the lingual surface of the MLI. (C) Digital radiography of the MLI with foramen cecum and absence of dens in dente. MLI, maxillary lateral incisor.
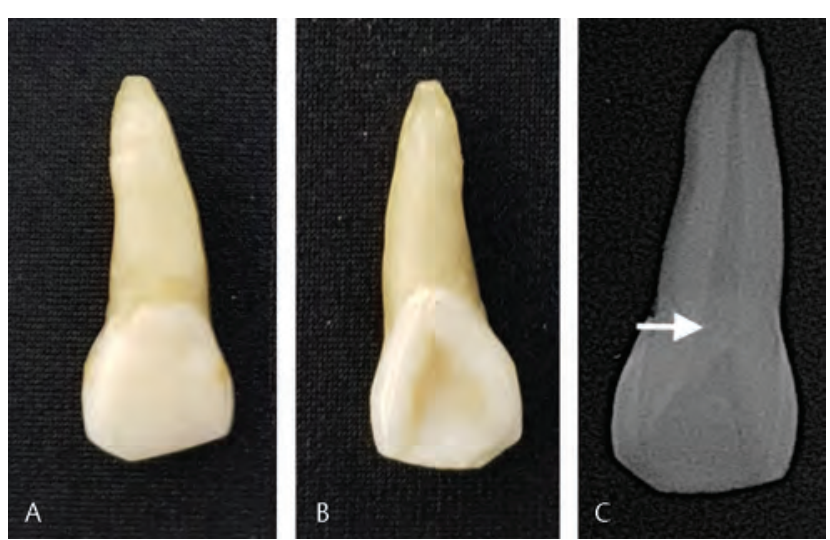

Fig. 3 (A) Morphology of the buccal surface of the MLI. (B) Morphology of the lingual surface of the MLI. (C) Digital and MLI radiography with dens in dente only. MLI, maxillary lateral incisor.
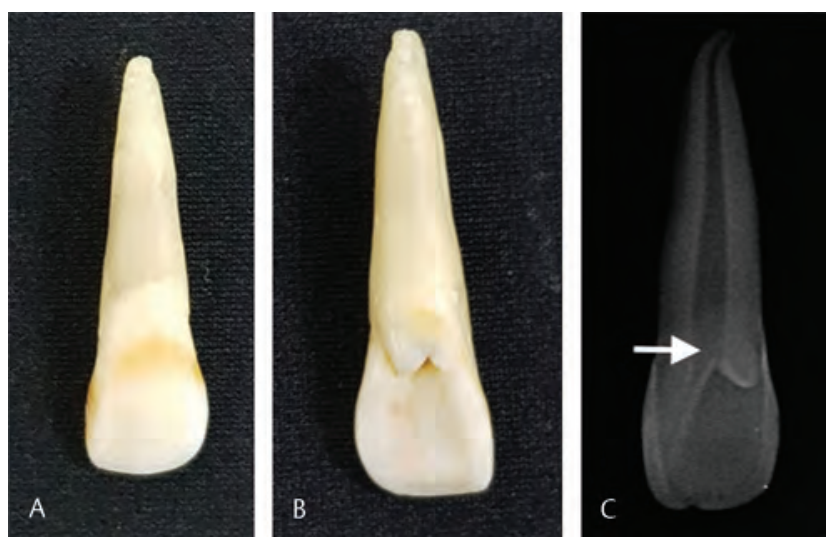

Fig. 4 (A) Morphology of the buccal surface of the MLI (B) Morphology of the lingual surface of the MLI. (C) Digital and MLI radiography with foramen cecum and dens in dente type I. MLI, maxillary lateral incisor.
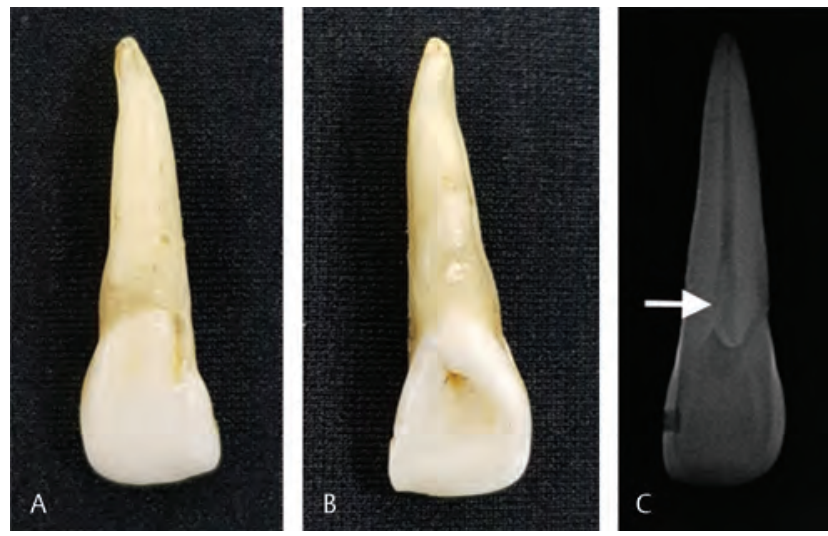

Fig. 5 (A) Morphology of the buccal surface of the MLI. (B) Morphology of the lingual surface of the MLI. (C) Digital and MLI radiography with foramen cecum and dens in dente type II. MLI, maxillary lateral incisor.

structure is rare. In the search for studies in the past 20 years, no research data were found in the literature regarding the frequency of foramen cecum, only observational reports mention that the foramen cecum is located between the cingulum and the lingual fossa presenting like a depression or small furrow shaped.

Based on the results of the present study, the frequency of the foramen cecum is extremely relevant information to verify the association of densities in the tooth and foramen cecum, in addition to understanding the normal morphology and anatomical variations of the MLI.

Understanding how morphological and clinical characteristics of tooth development abnormalities is essential to better understand the possible etiological effects involved and to elucidate preventive and therapeutic solutions. ${ }^{11,12}$ In addition, descriptions of dens in dente are based primarily 
on the radiographic findings and gross appearance. ${ }^{12-14}$ Some authors consider the pits in the tooth a deep fold of the foramen cecum during dental development, which in some cases may result in a second apical foramen. ${ }^{7,15,16}$

Cakici et al $^{17}$ reported that all teeth could be affected by this malformation. However, MLIs are the teeth with the most frequent malformation. This fact was demonstrated by Gündüz et $\mathrm{al},{ }^{18}$ who found that the most affected teeth were the MLIs (80.3\%), followed by the central incisors (19.02\%) and maxillary canines $(0.4 \%)$

Generally, men are more affected by dens in dente compared with women in a 2:1 ratio, and may vary by different ethnicities. ${ }^{3}$ In the present study, this relationship could not be verified.

However, dens in dente remains controversial. In the past decades, several theories have been proposed to explain the etiology of this anomaly: the dental arch growth pressure would result in an invagination of the enamel organ. Invagination would be a rapid and aggressive proliferation of a portion of the enamel's internal epithelium invading the papilla, considering it to be a "benign neoplasm of limited growth"; fusion of two dental germs; infection; trauma; protrusion of a part of the enamel organ that could lead to the formation of an enamel-coated canal ending at the cingulum and may be associated with the crown shape. ${ }^{15,19}$

This malformation can affect the clinical morphology of the dental crown, promoting an increase in the buccolingual distance, depending on the size of the invagination. Enamel may be hypoplastic and a deep groove that can be noticed and the tooth may have a crown against the case in more severe cases. ${ }^{20}$

Radiographically, a radiopaque invagination, very similar to enamel, is able to recognize an angle to a variable distance from the root. The defect may vary in size and shape, resembling a pear or a tooth within another tooth. ${ }^{20}$

Root canal morphology may also be altered..$^{21}$ Alani and Bishop, ${ }^{22}$ examining the root of an extracted tooth with this malformation, observed that the canal was irregular, with constrictions and dilatations.

Due to the anatomical complexity of teeth with dens in dente, the treatment is more complex, ranging from a simple technique to more invasive procedures. Conservative preventive treatment is the application of sealants to prevent caries, pulp infection, and premature tooth loss. Endodontic therapy is indicated when the tooth presents pulp involvement, and some modifications in endodontic therapy should be performed. ${ }^{8,23}$

Among the most invasive treatments, surgery with retrograde obturation may be necessary due to the impossibility of apical sealing. Surgical treatment is indicated in cases of conventional endodontic failure and the impossibility of access to the root canal system due to dental anatomy. ${ }^{24}$

However, due to the failure or inability to treat the root canal system, extraction is eventually necessary. Given the importance of early diagnosis for prevention, treatment, and preservation, it is important to observe anatomical structures such as the foramen cecum that may indicate the presence of dens in dente. With an initial conservative clinical treatment, it is possible to preserve the dental element, it can be seen that the analyzed teeth belonging to the collection, donated by dentists and students, may be the result of the lack of diagnosis and treatment because, if there is a diagnosis, treatment and preservation, perhaps there was no tooth loss due to tooth decay and endodontic problems due to the foramen cecum associated with dens in dente. Thus, it is of great importance to alert dentists about these structures.

In the present study, a statistically significant association between foramen cecum and dens in dente was found. Concomitant presence of foramen cecum and dens in dente was observed in $17.27 \%$ ( - Fig. 4), a high rate when compared with the presence of foramen cecum alone (9.09\%) (-Fig. 2) or dens in dente alone (8.18\%) (-Fig. 3).

In addition to the present study, only two studies published in the 1970s that evaluated the association of cecum foramen and dens in dente were found. Miyoshi et $\mathrm{al}^{25}$ analyzed the prevalence of dens in dente by clinical and radiographic examination. Dens in dente was present in $29.9 \%$ of the MLI and presence of cecum foramen in $13.3 \%$ of cases. Fujiki et $\mathrm{al}^{26}$ analyzed 1,532 MLI. The authors reported that 148 (9.66\%) MLIs presented dens in dente, and an important finding was the presence of the foramen cecum in $\sim 10 \%$ of the cases associated with dens in dente. A higher percentage was found in the present study (17.27\%).

According to Çolak et $a l,{ }^{27}$ the different types of dens in dente may be related to several factors, including differences in the study sample, geographical locations, gender differences, and chronological age. In a study with a Turkish population, it was observed that this malformation reached $0.17 \%$ of individuals, detected in 15 out of 192,150 teeth, with a prevalence of 0.008 , occurring in 12 MLIs and 3 maxillary canines. Type I was the most commonly found (73\%), followed by type II (20\%) and type III (7\%). Hamash and Alomari ${ }^{28}$ collected radiographs from a random sample of 1,660 patients from Jordan and found 61 teeth with dens in dente; the frequency was $2.95 \%$, and $90 \%$ of the dens in teeth found were in MLI and type I was the most found.

Type I is most commonly found according to Cakici et al (2010), who reported a frequency of type I (81.25\%), followed by type III (12.5\%). However, Gündüz et $\mathrm{al}^{18}$ verified type I preferentially (69.8\%), followed by type II (26.6\%) and subsequently type III (3.4\%). A study by Ceyhanli et $\mathrm{al}^{29}$ showed a higher frequency (86.6\%) in cases with type I, followed by type II (9.2\%) and type III (4.2\%). In our study, a higher frequency of type I dens in dente $(82.14 \%)$ and $17.86 \%$ in type II, and no type III dens in dente was observed.

Bilateral cases of dens in dente are also not uncommon, the bilateral incidence with symmetrical distribution was $25 \%$ in the study by Çolak et $\mathrm{al}^{27}$ and an evaluation performed Shi et $\mathrm{al}^{30}$ found that the bilateral occurrence was $19.05 \%$ of cases with dens in dente. 


\section{Conclusions}

An association was observed between the foramen cecum and dens in dente in the analyzed teeth. We emphasize the importance of alerting the dentist to the presence of a foramen cecum on the lingual surface of the MLI, as it is likely that dens in dente is usually of type I. Thus, the foramen cecum is a sign that can assist the surgeon-dentist in the discovery of dens in dente and clinical conduct to be taken.

\section{Conflict of Interest}

None declared.

\section{References}

1 Kulild JC, Weller RN. Treatment considerations in dens invaginatus. J Endod 1989;15(8):381-384

2 Costa WF, Sousa Neto MD, Pécora JD. Upper molar dens in dente-case report. Braz Dent J 1990;1(1):45-49

3 Crincoli V, Di Bisceglie MB, Scivetti M, Favia A, Di Comite M. Dens invaginatus: a qualitative-quantitative analysis. Case report of an upper second molar. Ultrastruct Pathol 2010;34(1):7-15

4 Oehlers FA. Dens invaginatus (dilated composite odontome). I. Variations of the invagination process and associated anterior crown forms. Oral Surg Oral Med Oral Pathol 1957;10(11):1204-1218

5 Thakur Narbir S, Seema T. Dens invaginatus (tooth within tooth). a review of the literature and diagnostic and management guidelines for practicing dentists. Indian Journal of Dental Sciences 2012;4:11-116

6 Ricucci D, Milovidova I, Siqueira JF. Unusual location of dens invaginatus, causing pulp involvement that is difficult to diagnose. J Endod 2020. Doi:10.1016/j.joen.2020.07.004

7 Schulze C. Developmental abnormalities of the teeth and the jaws. Thoma's Oral Pathology 1970;1:96-183

8 Hülsmann M. Dens invaginatus: aetiology, classification, prevalence, diagnosis, and treatment considerations. Int Endod J 1997;30(2):79-90

9 Fristad I, Molven O. Root resorption and apical breakdown during orthodontic treatment of a maxillary lateral incisor with dens invaginatus. Endod Dent Traumatol 1998;14(5): 241-244

10 Grahnen H, Lindahl B, Omnell K. Dens Invaginatus. I. A clinical, roentgenological and genetical study of permanent upper lateral incisors. Odontol Revy 1959;10:115-137

$11 \mathrm{Ng} \mathrm{KK}$, Rine S, Choi E, et al. Mandibular carnassial tooth malformations in 6 dogs-micro-computed tomography and histology findings. Front Vet Sci 2019;6:1-14

12 Kim CG, Lee SY, Kim JW, Park HM. Assessment of dental abnormalities by full-mouth radiography in small breed dogs. J Am Anim Hosp Assoc 2013;49(1):23-30
13 Pavlica Z, Erjavec V, Petelin M. Teeth abnormalities in the dog. Acta Vet Brno 2001;70:65-72

14 Zhang C, Hou BX. [Reconsideration of the diagnosis and treatment for dens invaginatus]. Zhonghua Kou Qiang Yi Xue Za Zhi 2020;55(5):302-308

15 Munir B, Tirmazi SM, Majeed HA, Khan AM, Iqbalbangash N. Dens invaginatus: aetiology, classification, prevalence, diagnosis and treatment considerations. Pak Oral Dent J 2011;31:191-198

16 Narayana P, Hartwell GR, Wallace R, Nair UP. Endodontic clinical management of a dens invaginatus case by using a unique treatment approach: a case report. J Endod 2012;38(8):1145-1148

17 Cakici F, Celikoglu M, Arslan H, Topcuoglu HS, Erdogan AS. Assessment of the prevalence and characteristics of dens invaginatus in a sample of Turkish Anatolian population. Med Oral Patol Oral Cir Bucal 2010;15(6):e855-e858

18 Gündüz K, Çelenk P, Canger EM, Zengin Z, Sümer P. A retrospective study of the prevalence and characteristics of dens invaginatus in a sample of the Turkish population. Med Oral Patol Oral Cir Bucal 2013;18(1):e27-e32

19 Bishop K, Alani A. Dens invaginatus. Part 2: clinical, radiographic features and management options. Int Endod J 2008;41(12):1137-1154

20 de Sousa SM, Bramante CM. Dens invaginatus: treatment choices. Endod Dent Traumatol 1998;14(4):152-158

21 Wayama MT, Valentim D, Gomes-Filho JE. Cintra LT, Dezan E Jr. 18-year follow-up of dens invaginatus: retrograde endodontic treatment. J Endod 2014;40(10):1688-1690

22 Alani A, Bishop K. Dens invaginatus. Part 1: classification, prevalence and aetiology. Int Endod J 2008;41(12):1123-1136

23 Gonçalves A, Gonçalves M, Oliveira DP, Gonçalves N. Dens invaginatus type III: report of a case and 10-year radiographic follow-up. Int Endod J 2002;35(10):873-879

24 Abu Hasna A, Ungaro DMT, de Melo AA, et al. Nonsurgical endodontic management of dens invaginatus: a report of two cases. F1000 Res 2019;8:1-10

25 Miyoshi S, Fujiwara T, Yamamoto K, Deguchi K. Dens invaginatus in Japanese incisors. J Oral Biol (Northborough) 1971;13:539-543

26 Fujiki Y, Tamaki N, Kawahara K, Nabae M. Clinical and radiographic observations of dens invaginatus. Journal Dentomaxillofac Radiology 1974;3:343-348

27 Çolak H, Tan E, Aylıkçı BU, Uzgur R, Turkal M, Hamidi MM. Radiographic study of the prevalence of dens invaginatus in a sample set of Turkish dental patients. J Clin Imaging Sci 2012;2:1-5

28 Hamasha AA, Alomari QD. Prevalence of dens invaginatus in Jordanian adults. Int Endod J 2004;37(5):307-310

29 Ceyhanli KT, Buyuk SK, Sekerci AE, Karatas M, Celikoglu M, Benkli YA. Investigation of dens invaginatus in a turkish subpopulation using conebeam computed tomography. Oral Health Dent Manag 2015;14:81-84

30 Shi S, Duan X, Shao J, Duan Q, Peng S. Dens invaginatus in ancient Chinese teeth of 2,000 years ago. Anat Rec (Hoboken) 2013;296(10):1628-1633 